(1)

CrossMark

\section{High-flow nasal cannula for COVID-19 patients: risk of bio-aerosol dispersion}

\author{
To the Editor:
}

We read with interest the article by Li et al. [1] entitled "High-flow nasal cannula for COVID-19 patients: low risk of bio-aerosol dispersion", recently published in the European Respiratory Journal. Although we do agree with the authors that high-flow nasal cannula (HFNC) might be an effective treatment for hypoxaemic coronavirus disease 2019 (COVID-19) patients, we believe that caution should be taken in considering HFNC in COVID-19 patients, as data about droplet dispersion and aerosol generation with HFNC are at least controversial [2]. The authors state that the scientific evidence of generation and dispersion of bio-aerosols via HFNC is similar to standard oxygen therapies. This statement is mainly based on the studies of Hui et al. [3] and Ip et al. [4], which showed that HFNC led to a smaller dispersion distance compared to non-rebreather and Venturi masks during exhaled smoke dispersion experiments. The assumption that the physical extent of exhaled air plumes is equal to the visible extent of exhaled smoke plumes is wrong: the visibility of smoke rapidly decreases when it mixes with clean air, but smoke particles do not disappear. In addition to that, the dispersion of small-sized smoke particles and aerosols is not identical to the dispersion of particles that have a broad range of sizes. These observations are important when studying the actual spread of viruses.

When a jet escapes from the mask, nose or mouth of a patient during ventilation therapy, virus-carrying droplets in the jet will follow different trajectories depending on their size. Each droplet of a specific size has a different terminal velocity, i.e. the vertical velocity that will be reached in quiescent air. Larger droplets carrying viral parts have a relatively high terminal velocity and will therefore deposit sooner than smaller droplets [5], which was recently confirmed by SOMSEN et al. [6]. However, patient-emitted aerosols (droplet diameter $<1 \mu \mathrm{m}$ ) are excellent passive tracers just like smoke particles; they have very small terminal velocities and can end up anywhere before ultimately leaving through the ventilation system. They also may contain viral parts that may remain viable for at least $3 \mathrm{~h}$ [7].

To estimate the dispersion of droplets, we have performed a passive-tracer visualisation using an anatomically correct 3D-printed head of a male adult, created using data from embodi3D [8], which were modified with the author's permission. Normal breathing was simulated, and HFNC and oxygen therapies were applied. The lung simulator consisted of a P1D-S050MS-0320 pneumatic cylinder (Parker, Cleveland, $\mathrm{OH}$, USA) driven by a PS01-37Sx120F-HP-N rigidly connected linear motor (LinMot, Spreitenbach, Switzerland). The applied breathing pattern, mimicking healthy tidal breathing, had a tidal volume of $475 \mathrm{~mL}$ and a respiratory rate of 15 breaths $\cdot \mathrm{min}^{-1}$. Smoke was generated using Miniax KS smoke patterns (Björnax AB, Nora, Sweden), consisting of particles between 0.3 and $2.5 \mu \mathrm{m}$, and inserted between the lung simulator and the 3D-printed head. The reflected light from the exhaled smoke was recorded using two cameras, and by combining these images, the extent of the exhaled air/smoke plumes was determined. From the distance and corresponding travelling time, air velocities during different therapies were estimated. Given the terminal velocity of $25 \mathrm{~cm} \cdot \mathrm{s}^{-1}$ for droplets with a diameter of $100 \mu \mathrm{m}$ (based on the theory of FlaGan and SEINFELD [5]) and assuming a typical height of the patient's nose compared to neighbouring surfaces of $10 \mathrm{~cm}$, a rough estimate of the dispersion range of large $(100 \mu \mathrm{m})$ droplets was obtained. The results are shown in table 1.

Our experiments show that the calculated air velocity during HFNC is larger than during oxygen therapies. Thus, the estimated dispersion distance of large droplets is also larger during HFNC compared to standard

@ERSpublications

HFNC seems to increase droplet spread, so caution should be taken if it is applied for COVID-19, and adequate protective measures should be provided. Further research on viral spread and risks associated with HFNC therapy in COVID-19 patients is needed. https://bit.ly/3gQjjrY

Cite this article as: Elshof J, Hebbink RHJ, Duiverman ML, et al. High-flow nasal cannula for COVID-19 patients: risk of bio-aerosol dispersion. Eur Respir J 2020; 56: 2003004 [https://doi.org/10.1183/ 13993003.03004-2020]. 
TABLE 1 Dispersion distances of exhaled smoke with visible concentration, and velocities and estimated dispersion ranges of large $(100 \mu \mathrm{m})$ droplets under different conditions

\begin{tabular}{|c|c|c|c|c|}
\hline Conditions & $\begin{array}{l}\text { Flow rate } \\
\mathrm{L} \cdot \mathrm{min}^{-1}\end{array}$ & $\begin{array}{c}\text { Dispersion distance of } \\
\text { exhaled smoke at } \\
\text { end-expiration } \mathrm{cm}\end{array}$ & $\begin{array}{l}\text { Calculated velocity } \\
\text { at } 0.5 \mathrm{~s} \text { after start } \\
\text { expiration } \mathrm{m} \cdot \mathrm{s}^{-1}\end{array}$ & $\begin{array}{c}\text { Estimated } \\
\text { dispersion range of } \\
\text { large droplets }{ }^{\#} \mathrm{~cm}\end{array}$ \\
\hline $\begin{array}{l}\text { Normal } \\
\text { breathing }\end{array}$ & & 36.3 & 0.46 & 18.5 \\
\hline \multicolumn{5}{|l|}{ HFNC } \\
\hline Small cannula & 30 & 71.2 & 0.65 & 26.2 \\
\hline Small cannula & 60 & 72.1 & 0.83 & 33.4 \\
\hline $\begin{array}{l}\text { Medium } \\
\text { cannula }\end{array}$ & 30 & 33.9 & 0.64 & 25.5 \\
\hline $\begin{array}{l}\text { Medium } \\
\text { cannula }\end{array}$ & 60 & 48.5 & 0.63 & 25.4 \\
\hline Large cannula & 30 & 25.4 & 0.47 & 18.8 \\
\hline Large cannula & 60 & 73.3 & 0.72 & 28.8 \\
\hline $\begin{array}{l}\text { Non-rebreather } \\
\text { mask }\end{array}$ & 15 & 20.3 & 0.38 & 15.1 \\
\hline \multicolumn{5}{|l|}{ Venturi mask } \\
\hline$F_{\mathrm{IO}_{2}} 0.4$ & 10 & 22.0 & 0.23 & 9.1 \\
\hline $\mathrm{F}_{\mathrm{IO}_{2}} 0.6$ & 15 & 33.7 & 0.26 & 10.3 \\
\hline
\end{tabular}

HFNC: high-flow nasal cannula; $F_{\mathrm{IO}_{2}}$ : inspiratory oxygen fraction. ${ }^{\#}$ : dispersion range of large droplets was estimated based on the air velocity at $0.5 \mathrm{~s}$ after start of expiration.

oxygen masks. Furthermore, the maximum range of visible smoke concentrations at the end of exhalation is larger during HFNC than during oxygen therapies, which contradicts the results of Hur et al. [3].

Due to the clear limitations of this relatively simple experiment, the aim is not to provide exact distances and velocities, but rather to gain awareness for the increased velocity levels of exhaled air during HFNC compared to other oxygen therapies, especially at higher flow rates. This strongly suggests that larger droplets are more widely dispersed by HFNC therapy than by other oxygen therapies.

We do believe that HFNC can be considered as a therapy for COVID-19 patients, but, if applied, caution should be taken and adequate protective measures should be provided [9]. It is quite clear that further research on viral spread and risks associated with HFNC therapy in COVID-19 patients is mandatory.

Judith Elshof $\oplus^{1,2}$, Rutger H.J. Hebbink ${ }^{3}$, Marieke L. Duiverman $\oplus^{1,2}$ and Rob Hagmeijer ${ }^{3}$

${ }^{1}$ Dept of Pulmonary Diseases/Home Mechanical Ventilation, University of Groningen, University Medical Center Groningen, Groningen, The Netherlands. ${ }^{2}$ Groningen Research Institute for Asthma and COPD (GRIAC), University of Groningen, Groningen, The Netherlands. ${ }^{3}$ Engineering Fluid Dynamics, University of Twente, Enschede, The Netherlands.

Correspondence: Judith Elshof, Dept of Pulmonary Diseases/Home Mechanical Ventilation, University of Groningen, University Medical Center Groningen, Hanzeplein 1, Groningen, The Netherlands. E-mail: j.elshof@umcg.nl

Received: 02 Aug 2020 | Accepted: 05 Aug 2020

Conflict of interest: J. Elshof reports grants from Vivisol BV and Fisher and Paykel Ltd, outside the submitted work. R.H.J. Hebbink reports grants and non-financial support from Fisher and Paykel Healthcare, outside the submitted work. M.L. Duiverman reports grants from Philips BV, Vivisol BV, and Fisher and Paykel Ltd, and grants and personal fees from Resmed Ltd, outside the submitted work. R. Hagmeijer has nothing to disclose.

\section{References}

1 Li J, Fink JB, Ehrmann S. High-flow nasal cannula for COVID-19 patients: low risk of bio-aerosol dispersion. Eur Respir J 2020; 55: 2000892.

2 Agarwal A, Basmaji J, Muttalib F, et al. High-flow nasal cannula for acute hypoxemic respiratory failure in patients with COVID-19: systematic reviews of effectiveness and its risks of aerosolization, dispersion, and infection transmission. Can J Anaesth 2020; 67: 1217-1248.

3 Hui DS, Chow BK, Lo T, et al. Exhaled air dispersion during high-flow nasal cannula therapy versus CPAP via different masks. Eur Respir J 2019; 53: 1802339.

4 Ip M, Tang JW, Hui DSC, et al. Airflow and droplet spreading around oxygen masks: a simulation model for infection control research. Am J Infect Control 2007; 35: 684-689.

5 Flagan RC, Seinfeld JH. Fundamentals of Air Pollution Engineering. Englewood Cliffs, Prentice-Hall, 1988.

6 Somsen GA, van Rijn C, Kooij S, et al. Small droplet aerosols in poorly ventilated spaces and SARS-CoV-2 transmission. Lancet Respir Med 2020; 8: 658-659. 
7 van Doremalen N, Bushmaker T, Morris DH, et al. Aerosol and surface stability of SARS-CoV-2 as compared with SARS-CoV-1. N Engl J Med 2020; 382: 1564-1567.

8 embodi3D. Easily Create 3D Printable Muscle and Skin STL Files from Medical CT Scans. www.embodi3d.com/ blogs/entry/353-easily-create-3d-printable-muscle-and-skin-stl-files-from-medical-ct-scans/ Date last updated: 30 October 2016. Date last accessed: 16 June 2019.

9 Vianello A, Arcaro G, Molena B, et al. High-flow nasal cannula oxygen therapy to treat patients with hypoxemic acute respiratory failure consequent to SARS-CoV-2 infection. Thorax 2020; in press [https://doi.org/10.1136/ thoraxjnl-2020-214993].

Copyright (CERS 2020.

This version is distributed under the terms of the Creative Commons Attribution Non-Commercial Licence 4.0. 